\title{
Research on Financial Risk Evaluation and Risk Control Strategies of China's Construction Enterprises - Taking X Construction Company as an Example
}

\author{
Wenhao Jiao*1 \\ ${ }^{1}$ Financial Department General Construction Company of CCTEB Group Co.,LTD(South China) Shenzhen, China
}

\begin{abstract}
China's construction industry has continued to develop for decades, and the industry is extremely competitive, resulting in high debt ratios for construction companies. The high gearing ratio can bring huge financial risks to the enterprises and jeopardize the future development of the enterprises. To address this problem, this paper takes $\mathrm{X}$ construction company as the research object, analyzes the financial risk control status of the company, and Optimizes the financial risk evaluation system of $\mathrm{X}$ construction company based on the analysis results using the hierarchical analysis method to assess the financial risk of the company, and proposes corresponding control strategies in order to solve and improve the specific problems exposed in the financial risk control of $\mathrm{X}$ construction company, and provide a better solution to the financial risk control of $\mathrm{X}$ construction company. The purpose is to solve and improve the specific problems revealed in the financial risk control of $\mathrm{X}$ construction company, and to provide reference for the current financial risk control research of construction enterprises.
\end{abstract}

\section{Introduction}

The construction industry has developed rapidly since China's reform and opening up, but the high gearing ratio at the same time of development means that the financial risk of construction enterprises is relatively high, which may bring about insufficient cash flow and easily lead to a break in the enterprise's capital chain and the enterprise's inability to repay debts in time, thus leading to the possibility of bankruptcy. As a special industry, the construction industry is characterized by many uncertainties, which is one of the reasons for the high gearing ratio, and the high gearing ratio in the construction industry has a long history [1-3]. As the financial risk of the construction industry is more prominent, if we ignore the financial risk arising from the production and operation activities, it may bring huge losses to the enterprise. Nowadays, financial risk management has become one of the important tasks in the production and operation of each construction enterprise, which has an important impact on the development and stability of the enterprise [4-6]. Financial risk control is directly related to the future profitability and development of the enterprise, the better the financial risk control, the more helpful to the development of the enterprise, on the contrary, it will bring harm to the enterprise, the degree of danger is positively related to the risk control [7-8].

By studying the control strategies of the financial risk control problem of construction companies, with a view to providing reference for the financial risk control of similar construction companies, and by using the solutions of this financial risk control in the implementation and application in the production and operation of similar enterprises, we can prevent the possible harm brought to the enterprise by the financial risk, and at the same time reduce the unnecessary losses brought to the enterprise. Therefore, it is necessary to study the financial risk control of construction companies. Based on this research background, this paper takes $\mathrm{X}$ construction company as an example, analyzes the current problems of financial risk control of $\mathrm{X}$ construction company, evaluates the financial risk of $\mathrm{X}$ construction company and proposes relevant financial risk control measures in order to reduce the financial risk of $\mathrm{X}$ construction company.

\section{Analysis of the current situation of financial risk control of $X$ construction company}

\subsection{Company Overview}

$\mathrm{X}$ construction company is a large construction enterprise integrating architectural design, building decoration and renovation, upper wood engineering, and property management into one business. In order to analyze the operations of $\mathrm{X}$ construction company, its financial statements for 2017-2020 were compiled as shown in Table I. 
TableI. Financial statements of X Construction Company

\begin{tabular}{|c|c|c|c|c|}
\hline $\begin{array}{c}\text { Category } \\
\text { (Million } \\
\text { Yuan) }\end{array}$ & $\mathbf{2 0 1 7}$ & $\mathbf{2 0 1 8}$ & $\mathbf{2 0 1 9}$ & $\mathbf{2 0 2 0}$ \\
\hline $\begin{array}{c}\text { Operating } \\
\text { income }\end{array}$ & 3043.17 & 3350.28 & 3519.08 & 3830.12 \\
\hline Net profit & 91.70 & 151.81 & 164.93 & 180.02 \\
\hline Current assets & 3223.22 & 3681.99 & 4251.17 & 4550.34 \\
\hline Total assets & 9221.92 & 9956.83 & 10102.05 & 11054.79 \\
\hline $\begin{array}{c}\text { Current } \\
\text { liabilities }\end{array}$ & 4655.25 & 4506.70 & 4855.92 & 4840.28 \\
\hline $\begin{array}{c}\text { Total } \\
\text { liabilities }\end{array}$ & 6933.71 & 7620.23 & 7751.36 & 8546.90 \\
\hline $\begin{array}{c}\text { Gearing ratio } \\
\text { (\%) }\end{array}$ & 75.19 & 76.53 & 76.73 & 77.31 \\
\hline $\begin{array}{c}\text { Inventory } \\
\text { turnover Ratio }\end{array}$ & 4.01 & 4.51 & 4.76 & 4.69 \\
\hline $\begin{array}{c}\text { Accounts } \\
\text { receivable } \\
\text { turnover ratio }\end{array}$ & 4.96 & 6.57 & 7.39 & 7.21 \\
\hline $\begin{array}{c}\text { Net operating } \\
\text { margin (\%) }\end{array}$ & 3.01 & 4.53 & 4.69 & 4.70 \\
\hline
\end{tabular}

The financial data in the table shows that the total assets of the company are increasing, but at the same time the total liabilities are also increasing, and the overall current liabilities ratio is also gradually increasing, which is due to the increasing short-term liabilities, and the shortterm liabilities have a short repayment period, so if the company needs a lot of money to repay the debts in the short term, it will definitely affect the normal operation of the enterprise, and the financial risk will also increase. At the same time, the company's gearing ratio is too high, which represents the financial risk faced by $\mathrm{X}$ Construction Company. When the expected output value is not completed to bring the company a certain amount of revenue, it may lead to a break in the capital chain and the debt due cannot be repaid, which will bring losses to the enterprise.

\subsection{Current State of Financial Risk Control of X Construction Company}

\subsubsection{Current state of control of fundraising activities}

Since gearing ratio of $\mathrm{X}$ construction company is higher than the industry average and the company has a single source of financing, the main risk control measure used by $\mathrm{X}$ construction company is to maximize the amount of long-term bank loans and reduce the amount of short-term loans when financing. Through the optimization of debt maturity, and the maintenance of good credit relations and credit of the company, the financial risks arising from financing activities are dispersed as much as possible. The control of financing risks is mainly at the stage of financing decisions. The company's financing decision is made by the finance department, which provides financing proposals, and then the finance director reviews and selects the optimal proposal before the finance manager and general manager review it. If the finance manager and general manager do not pass the review, the finance department re-screens the financing proposal. If the proposal is approved, the finance department prepares a feasibility report on the financing proposal, and then implements it after it is approved by the finance supervisor and the finance manager and general manager.

\subsubsection{Current State of control of investment activities}

$\mathrm{X}$ construction company pays great attention to investment activities and has a strategic development department, which is responsible for screening suitable investment projects for the company. Based on the company's long-term strategic plan, the strategic development department searches for and identifies investment projects and conducts preliminary investigations before preparing project proposals, which are subsequently approved by the manager. After the manager's approval, the strategic development department prepares a feasibility report, and if the manager does not approve it, it is necessary to re-investigate or abandon the investment project. After the feasibility report is approved by the manager, it is included in the company's annual plan, and conversely, the feasibility report is re-prepared or the investment project is abandoned. The company selects investment projects based on strategic objectives by comparing them, and tries to choose high quality projects with high gold content, low risk and stable income to avoid possible losses caused by financial risks. For projects with less difference, the selection can be made by comparing the project cost, and the risk can also be transferred by purchasing insurance and subcontracting the higher risk projects.

\subsubsection{Current state of control of operating activities}

Most companies generally use risk retention to deal with financial risks arising from their operating activities, i.e., they fully accept possible financial risks. Of course, some necessary measures are chosen to prevent financial risks before they occur. However, X construction company did not choose any control measures for the financial risks arising from operating activities, but only chose risk retention, which is likely to bring huge losses to $\mathrm{X}$ construction company after the financial risks occur because it did not choose some measures to cope with them.

\subsubsection{Current state of control of cash flow activities}

Companies should develop different control measures for financial risks in cash flow activities based on different reasons. However, X Construction Company has extremely limited cash flow management and only chooses the control method of risk retention with no other supporting measures.

\section{Optimization of financial risk evaluation system of $X$ construction company}

Through the analysis of the basic situation of $\mathrm{X}$ construction company, it can be seen that the use of the existing financial risk evaluation indicators of the 
company is not standardized and backward, therefore, it is necessary to optimize the existing financial risk indicators of $\mathrm{X}$ construction company and make appropriate improvements to the evaluation of financial risks.

\subsection{Selection of Financial Risk Evaluation Indicators}

In this paper, financial risk evaluation indicators are divided into three categories including target, criterions, and evaluation indicators. The financial risk evaluation is the target, the criterions include profitability, operating capacity, solvency and growth capacity, respectively. The evaluation indicators are finalized according to the operating condition of $\mathrm{X}$ construction company. The specific financial risk indicators are shown in Table II.

TableII. financial risk evaluation indicators

\begin{tabular}{|c|c|c|}
\hline Target & Criterions & Evaluation indicators \\
\hline \multirow{14}{*}{$\begin{array}{c}\text { Financial } \\
\text { risk } \\
\text { evaluation } \\
\text { (I) }\end{array}$} & \multirow{4}{*}{ Profitability $\left(\mathrm{I}_{1}\right)$} & Cost margin $\quad\left(I_{11}\right)$ \\
\hline & & Return on total assets $\left(I_{12}\right)$ \\
\hline & & Return on net assets $\left(I_{13}\right)$ \\
\hline & & Operating profit ratio $\left(\mathrm{I}_{14}\right)$ \\
\hline & \multirow{3}{*}{$\begin{array}{l}\text { Operating } \\
\text { capacity } \\
\left(\mathrm{I}_{2}\right)\end{array}$} & $\begin{array}{l}\text { Current assets turnover ratio } \\
\left(\mathrm{I}_{21}\right)\end{array}$ \\
\hline & & Inventory turnover ratio $\quad\left(\mathrm{I}_{22}\right)$ \\
\hline & & $\begin{array}{c}\text { Accounts receivable turnover } \\
\text { ratio }\left(\mathrm{I}_{23}\right)\end{array}$ \\
\hline & \multirow{4}{*}{ Solvency $\left(\mathrm{I}_{3}\right)$} & Current ratio $\quad\left(\mathrm{I}_{31}\right)$ \\
\hline & & Quick ratio $\quad\left(I_{32}\right)$ \\
\hline & & Gearing ratio $\left(\mathrm{I}_{33}\right)$ \\
\hline & & Interest cover multiplier $\quad\left(\mathrm{I}_{34}\right)$ \\
\hline & \multirow{3}{*}{$\begin{array}{c}\text { Growth capacity } \\
\qquad\left(\mathrm{I}_{4}\right)\end{array}$} & Operating growth rate $\left(\mathrm{I}_{41}\right)$ \\
\hline & & Total assets growth rate $\left(\mathrm{I}_{42}\right)$ \\
\hline & & $\begin{array}{l}\text { Capital preservation and } \\
\text { appreciation ratio }\left(\mathrm{I}_{43}\right)\end{array}$ \\
\hline
\end{tabular}

\subsection{Calculation of Indicator Weights}

\subsubsection{Delphi method}

In this paper, a panel of six corporate financial risk practitioners and four university finance teachers were invited to score the financial risk indicators. The Delphi method is applied as follows.

Step 1: the location characteristics $C_{i}$ were counted based on the collected data.

$$
C_{i}=\frac{1}{N} \sum_{j-1}^{5} S_{j} n_{i j}
$$

where $C_{i}$ denotes the concentration of experts' opinions on the $i$-th indicator, and $S_{j}$ denotes the score of indicator $i$ corresponding to the $j$-th level of importance.

Step 2 : the data are analyzed for the dispersion degree $\Theta$ based on the statistical results, and the consistency of the data distribution is tested. The variation coefficient $V$ is formulated as follows:

$$
\begin{aligned}
& \Theta_{i}=\sqrt{\frac{1}{M-1}} \sqrt{\sum_{i-1}^{5} n_{i j}\left(X_{i}-C_{i}\right)^{2}} \\
& V_{i}=\frac{\Theta_{i}}{C_{i}}
\end{aligned}
$$

The value of $\Theta_{i}$ is inversely proportional to the degree of concentration of expert opinions. Since the above are absolute indicators, there can be situations where the performance results of each indicator are inconsistent. When this possibility occurs, since $V_{i}$ is inversely proportional to $C_{i}$, the coefficient of variation is inversely proportional to the concentration of expert opinion, and the result of $V_{i}$ prevails.

\subsubsection{Hierarchical analysis method}

The hierarchical analysis method solves the problem of systematizing some complex and irregular data associated with constituent factors in the economy to make a scientific basis for decision making. The specific steps are as follows:

Step 1: the financial risk evaluation indicators are classified. The factors are sorted out and organized to form a hierarchical classification.

Step 2: constructing a judgment matrix. On the basis of the hierarchical framework of financial risk evaluation indicator structure, the judgment matrix is obtained by comparing any two financial risk evaluation indicators of the same level and judging the importance of the two financial risk evaluation indicators and assigning values to the indicators. In the comparison process, since the indicators need to be transferred from qualitative to quantitative, it is necessary to introduce judgment scales, and the common method of judgment scales from 1 to 9 is used, based on $a_{i j}>0, a_{i j}=1, a_{i j}=1 / a_{i j}$.

Step 3: Calculate the eigenvalues and eigenvectors

In step 2, several judgment matrices are derived based on the classification, and the maximum eigenvalues and eigenvectors are calculated by the judgment matrix. I often use the root method or summation method to calculate the results, as follows:

First, the $n$-th root of the product of the elements of each row of the judgment matrix is calculated.

$$
W_{i}=\sqrt{\prod_{i=1}^{n} a_{i j}}(\mathrm{i}=1,2, \cdots, n)
$$

Second, normalizing the $W_{i}$

$$
W_{i}^{0}=\frac{W_{i}}{\sum_{i}^{n} W_{i}}
$$

$\boldsymbol{W}=\left(W_{1}, W_{2}, \cdots, W_{n},\right)$ is then the approximation of the eigenvector of the judgment matrix.

Finally, the maximum eigenvalue $\lambda_{\text {max }}$ corresponding to the eigenvector $\boldsymbol{W}$ is calculated

$$
\lambda_{\max }=\frac{1}{n} \sum_{i} \frac{(\boldsymbol{A} \boldsymbol{W})_{i}}{W_{i}}
$$

Step 4: Performing a consistency check on the matrix

Since not all matrices can satisfy the consistency, a one-time test is performed on the matrix. 
For the various indicators of financial risk evaluation of $\mathrm{X}$ construction company, the financial risk levels were summarized and classified by using the efficacy coefficient method and the calculation of the standard values of corporate performance evaluation. The weights and risk indices of each financial risk evaluation indicators were calculated, and the comprehensive financial risk indexes was calculated by weighted average of the two numbers, and the financial risk level of $\mathrm{X}$ construction company was classified according to the magnitude of the values. In this paper, the financial risk level is set according to the actual situation of $\mathrm{X}$ construction company, as shown in Table III below.

TableIII. Financial risk level classification

\begin{tabular}{|c|c|}
\hline Financial risk levels & Financial risk composite indexes \\
\hline Low risk & $(85,100]$ \\
\hline Lower risk & $(75,85]$ \\
\hline Moderate risk & $(65,75]$ \\
\hline High risk & $(55,65]$ \\
\hline Higher risk & $(0.55]$ \\
\hline
\end{tabular}

According to the calculation results of the weights of the financial risk control evaluation indicator, we can calculate financial risk composite index $=$ the sum of (individual risk index $\times$ the weight of the index) / the sum of the weights. With the help of yaahp software, we calculated that the financial risk index of $\mathrm{X}$ construction company in 2018 is 77.0782 . Similarly, we calculated that the financial risk index of X construction company in 2019 is 78.8091 and in 2020 is 72.3368 . Based on the set risk level, we determined that $\mathrm{X}$ construction company in 2018-2019 is low risk and in 2020 is medium risk. The risk level in 2020 has increased by one level compared to 2018 , 2019, which means a greater financial risk than in 2018, 2019

\section{Financial Risk Control Strategies}

According to the current financial risk situation of $\mathrm{X}$ construction company, combined with the actual situation of the company, in order to control the financial risk within an acceptable range, this paper proposes some control strategies to achieve the purpose of controlling the financial risk.

(1) The increase in the scale of indebtedness brings about a high gearing ratio and at the same time places a heavy burden on the solvency of the company. However, the company needs a large amount of capital to maintain in order to seek growth. Therefore, the company should pay attention to the two-sided impact brought by the scale of debt, and a reasonable financing structure plays a key role in the future profitability of the company, and eliminate the negative impact caused by the excessive scale of debt by optimizing the capital structure of the company.

(2) The income generated from investment activities is part of the company's income. Blind investment makes the company short of capital and also brings huge losses to the company, therefore, the feasibility analysis of the investment plan should be strengthened. As a part of the company's overall strategic objectives, the company should also set investment objectives, profitability objectives, etc. and choose appropriate investment plans in conjunction with the company's unique advantages to actively promote the realization of the company's overall strategic objectives. The efficiency of the use of funds is the key point and difficulty of investment funds management. In addition, the efficiency of the use of funds is related to the development and even the survival of the company, and investment funds, as part of the use of the company's funds, should also strengthen the management of the use of investment funds.

(3) Inventory of construction enterprises includes engineering construction and raw materials, low-value consumables, etc.. Inventory management system should be formulated according to different detailed sections, and the management of inventory should be strengthened at the same time. Construction enterprises construction site financial risk control focus on preventing material procurement risk and waste, the management of materials is heavy and complex, enterprises must strengthen the internal control system, scientific and effective management. This can effectively reduce the financial risk brought by inventory.

(4) Construction enterprises need strong cash flow to maintain the normal operation of the company. The company should prepare a cash flow budget based on a comprehensive budget by determining the expected cash income and expenditure. In the case of sufficiency, the enterprise should consider whether the use of funds is not efficient enough, and improve the efficiency of use by increasing the use of funds. If funds are not If funds are not sufficient, the enterprise needs to solve the problem of insufficient funds through external financing or internal financing.

\section{Conclusion}

This paper first selects the main financial data of $\mathrm{X}$ construction company for financial risk assessment based on its financial risk situation, and then proposes financial risk control strategies for $\mathrm{X}$ construction company's financial risk, which is beneficial to $\mathrm{X}$ construction company to improve its ability to prevent financial risk. Through the analysis, we can learn that the financial risk of $\mathrm{X}$ construction company has a rising trend, but the existing risk control system still has many shortcomings, and in the future, we need to organize more special training, strengthen the introduction and training of talents, improve the risk awareness of all employees, keep up with the times, improve the identification and control measures of risk control, and promote the sustainable and healthy development of the enterprise.

\section{References}

1. ZhenXing $\mathrm{Hu}$ and $\mathrm{Xiang} \mathrm{Hu}$, "On financial risk and its control," 2011 2nd International Conference on Artificial Intelligence, Management Science and Electronic Commerce (AIMSEC), Dengleng, 2011, 
pp. 2212-2214.

2. Lijun Li, Lei Wang and Liping Yu, "Research of financial risk warning model of listed companies in the Supply Chain environment," 2012 24th Chinese Control and Decision Conference (CCDC), Taiyuan, 2012, pp. 3441-3445.

3. T. Xin-shu and Li Wei, "The Study on the Application of Value at Risk in Inventory Control," 2007 IEEE International Conference on Control and Automation, Guangzhou, China, 2007, pp. 2740-2743.

4. Liu Jingzhong, "On the corporate financial risk early warning and control," 2010 International Conference on Future Information Technology and Management Engineering, Changzhou, 2010, pp. 267-269.

5. X. Guo, "Research on Enterprise Financial Risk Control Based on Intelligent System," 2019 12th International Conference on Intelligent Computation Technology and Automation (ICICTA), Xiangtan, China, 2019, pp. 529-534.

6. R. Li, "Research on problem of prevention and control of the listed companies' financial risk in China," 2010 International Conference on Future Information Technology and Management Engineering, Changzhou, 2010, pp. 487-491.

7. K. Wang et al., "Intelligent Text Mining Based Financial Risk Early Warning System," 2015 2nd International Conference on Information Science and Control Engineering, Shanghai, 2015, pp. 279-281.

8. H. Cuiping, "Research on the transmission mechanism of enterprises financial risk," 2011 International Conference on Product Innovation Management (ICPIM 2011), Wuhan, 2011, pp. 661664. 